\title{
A survey of breakfast practices of 4-12 year old children
}

\author{
M P Senanayake ${ }^{1}$, H M L N Parakramadasa ${ }^{2}$ \\ Sri Lanka Journal of Child Health, 2008; 37: 112-117
}

(Key words: Breakfast practices, children)

\begin{abstract}
Objectives To assess time of intake of breakfast and choice of food consumed by school children, identify underlying reasons for prevailing breakfast practices and describe the knowledge and attitude of mothers about the nutritional needs of their children in relation to breakfast .
\end{abstract}

Study design A descriptive cross sectional study using an interviewer administered questionnaire.

Study setting A medical ward at Lady Ridgeway Hospital for Children, Colombo

Study population Children aged 4-12 years, admitted to the professorial ward with an acute illness of less than three days duration between $1 \mathrm{st}$ December 2006 and 28th February 2007. Exclusion criteria were severe or chronic illness, food allergy, dietary restrictions, special diet schedules, growth abnormality/ties or developmental delay.

Method A modified food frequency questionnaire was used to gather data on demographic and dietary details. Consumption patterns of five commonly eaten food groups were investigated based on dietary recall. Portion sizes and nutritive values were not assessed.

Results Of a total of 220 children, 96\% were school-going. Majority $(81 \%)$ were resident in the Western province and were represented by Sinhalese (79.5\%), Tamils (10.5\%) and Muslims $(10 \%)$. All mothers were literate and $60 \%$ had studied up to or above GCE (O Levels). In $80 \%$ monthly family income was above Rs. 8000. Population studied comprised mostly of primary school children. Male to female ratio was 1:1.08 and no significant differences in breakfast practices or nutritional status were found between sexes.

${ }^{1}$ Professor, Department of Paediatrics, Faculty of Medicine, University of Colombo, ${ }^{2}$ Registered Medical Officer, Lady Ridgeway Hospital, Colombo.

(Received on 25 March 2008. Accepted on 28 March 2008)
Of 211 school children, only $63(30 \%)$ ate breakfast and $70 \%$ left home without breakfast. First food consumed by $90 \%$ was a beverage i.e. tea with milk (70\%), full cream milk (16\%). Rice or rice flour based cooked food was consumed by $51 \%$ and wheat flour based foods by $36 \%$. Home cooked meals were provided for $85 \%$ of children but $67 \%$ preferred to eat fast foods. No significant difference was found in breakfast practices between the underweight and normal weight children.

All mothers said "breakfast is essential" but only $64 \%$ thought that a balanced meal was necessary for breakfast. Fast foods were the most liked food items and wheat flour based items came next. Rice was the first preference in only $18 \%$.

Conclusions Majority of children left for school without breakfast and ate during the mid- morning break. Although home cooked rice meals were provided the preferred breakfast food was bread or wheat flour based foods. Fast foods were the most liked food items. Intake of fruit was very low among school children surveyed. We recommend that schools either provide breakfast or time for consuming the food that was brought from home, before start of lessons.

\section{Introduction}

Breakfast is the first and probably the most important meal of the day. In addition to providing energy, it improves mental powers and concentration,, IQ, and participation in physical activities $^{1,2,3}$. One fourth to one third of the daily recommended nutrients are expected to be provided with breakfast ${ }^{4}$ but changing life styles and altered food consumption patterns may cause children to miss out on this all important meal. We investigated the breakfast practices of a cohort of children aged $4-12$ years. The knowledge and attitude of mothers towards their child's eating behaviour, nutritional needs and the association between socio-demographic factors and food habits are also described. 


\section{Objectives}

- To assess time of intake of breakfast and choice of food consumed by school children.

- To identify underlying reasons for prevailing breakfast practices.

- To describe the knowledge and attitude of mothers about the nutritional needs of their children in relation to breakfast.

\section{Study design}

A descriptive cross sectional study using an interviewer administered questionnaire.

\section{Study setting}

A medical ward at Lady Ridgeway Hospital for Children, Colombo

\section{Study population}

Children aged 4-12 years, admitted to the professorial ward with an acute illness of less than three days duration between 1st December 2006 and 28th February 2007. Exclusion criteria were severe or chronic illness, food allergy, dietary restrictions, special diet schedules, growth abnormality/ties or developmental delay.

\section{Method}

All children between 4-12 years, admitted for indoor care to the Professorial paediatric ward with an acute illness of one to three days duration, were serially enrolled after obtaining informed consent from their parents or guardians. Those with chronic illness (including bronchial asthma), food allergies, medically indicated dietary restrictions, special diet schedules, abnormalities of growth or delay in development, and patients who were severely ill, were excluded.

A modified pre-tested food frequency questionnaire was used by one of the co-authors who visited the ward daily to interview mothers on demographic and dietary details. Dietary recall was used to assess food frequency. Food preparation, nutritional knowledge and attitude towards breakfast, frequency of consumption by the child during times of good health of specified food over an average week, in the past three months were recorded, based on dietary recall. Consumption patterns of commonly eaten items starting from the first food or beverage in the morning until the first proper solid meal were described according to five groups of food items. Frequency of intake was graded into four categories varying from "never or less than once a week to four or more times a week". Portion sizes and nutritive components of mixed dishes were not assessed. Ethical clearance was obtained from the Ethics Review Committee of the Faculty of Medicine Colombo and MS EXCEL used for data analysis.

\section{Results}

The study involved 220 children of whom 211 $(96 \%)$ were school-going. Majority $(81 \%)$ were resident in the Western province and all major ethnic groups in the country were represented; Sinhalese 176 (79\%), Tamil 24 (11\%) and Muslim $20(10 \%)$. All mothers interviewed were literate and $60 \%$ were educated up to or above GCE (O Levels). The family income was above Rs. 8000 per month in $80 \%$ (Table 1). Population studied comprised mostly of primary school children. Age distribution is shown in Table 1. Male to female ratio was 1:1.08 and no significant differences in breakfast practices or nutritional status were found between sexes. Nutritional status was within $3^{\text {rd }}$ and $97^{\text {th }}$ centiles for age in $80 \%$ in height and $60 \%$ in weight in the children studied

We found that of the 211 school children, only 63 $(30 \%)$ ate breakfast before leaving home. On waking up the first food consumed was a beverage in $199(90 \%)$ and most frequently consumed items were "tea with milk" $154(70 \%)$, full cream milk $35(16 \%)$, and plain tea $9(4 \%)$. The food frequency questionnaire assessed the daily intake of the first meal categorized into five major food groups (Table 2). Rice or rice flour based cooked food was the most frequently consumed food item, by 111 $(51 \%)$ and wheat flour based foods came next, 79 $(36 \%)$. Home made meals were provided by 188 $(85 \%)$ of respondents, but $147(66.8 \%)$ of the participating children preferred fast foods. We found the intake of fruit at breakfast to be very low with $138(70 \%)$ never consuming fruit in the morning. A further $38(17 \%)$ said their weekly intake of fruit was on less than two mornings. 
Table 1

Demographic characteristics of child participants $(n=200)$

\begin{tabular}{|c|c|c|}
\hline & Number & $\%$ \\
\hline \multicolumn{3}{|l|}{ Age (yrs) } \\
\hline 4 to 5 & 46 & 20.9 \\
\hline 5 to 10 & 138 & 62.7 \\
\hline 10 to 12 & 36 & 16.4 \\
\hline \multicolumn{3}{|l|}{ Ethnicity } \\
\hline Sinhalese & 176 & 79.5 \\
\hline Tamil & 24 & 20.5 \\
\hline Muslim & 20 & 10.0 \\
\hline \multicolumn{3}{|l|}{ Level of schooling } \\
\hline Not schooling & 09 & 4.1 \\
\hline Nursery school & 37 & 16.8 \\
\hline Primary school & 138 & 62.7 \\
\hline Secondary school & 36 & 16.4 \\
\hline \multicolumn{3}{|l|}{ Mother's education } \\
\hline None & 06 & 2.9 \\
\hline Grade $1-5$ & 15 & 6.8 \\
\hline Grade 6-9 & 46 & 20.9 \\
\hline GCE ( O Level & 86 & 39.1 \\
\hline GCE ( A level) & 59 & 26.8 \\
\hline University & 08 & 3.7 \\
\hline \multicolumn{3}{|l|}{ Family income ( SL Rupees) } \\
\hline Below Rs. 3000 & 0 & 0 \\
\hline Rs 3000 - Rs 5000 & 18 & 8.2 \\
\hline Rs 5000 - Rs 8000 & 26 & 11.8 \\
\hline Rs. 8000 - Rs 10,000 & 64 & 29.0 \\
\hline Above Rs. 10,000 & 112 & 51.0 \\
\hline \multicolumn{3}{|l|}{ Mother's employment } \\
\hline Housewife & 179 & 81.4 \\
\hline Full/ part time employment & 41 & 8.6 \\
\hline
\end{tabular}


Table 2

Breakfast Practices $(\mathbf{n}=\mathbf{2 2 0})$

\begin{tabular}{|c|c|c|}
\hline 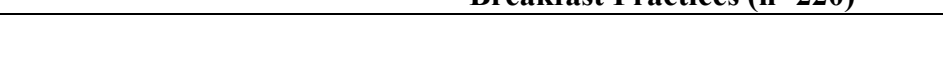 & Number & $\%$ \\
\hline \multicolumn{3}{|l|}{ Type of beverage taken on waking $(>=4 \mathrm{~d} / \mathrm{wk})$} \\
\hline Full cream milk & 35 & 15.9 \\
\hline Tea with milk & 154 & 70.0 \\
\hline Plain tea & 09 & 04.1 \\
\hline Others ( eg Kola kenda) & 01 & 0.5 \\
\hline None & 21 & 09.5 \\
\hline \multicolumn{3}{|l|}{ Most frequently consumed food item } \\
\hline Rice or rice based food (Hoppers, string hoppers, kiribath, pittu etc) & 111 & 50.5 \\
\hline Bread or wheat flour based food (Buns, biscuits, roti etc) & 79 & 35.9 \\
\hline Pulses (Green gram, cowpea) & 21 & 09.5 \\
\hline Fast food (Rolls, pastries, patties) & 08 & 03.6 \\
\hline Tubers and roots & 01 & 0.5 \\
\hline \multicolumn{3}{|l|}{ Most preferred food item } \\
\hline Fast foods & 83 & 37.7 \\
\hline Wheat flour based food & 64 & 29.1 \\
\hline Rice flour based food & 40 & 18.2 \\
\hline Pulses & 18 & 08.2 \\
\hline Ready-mix cereals (Samaposha, Thriposha) & 15 & 06.8 \\
\hline \multicolumn{3}{|l|}{ Weekly fruit intake } \\
\hline 4 or more days & 05 & 02.3 \\
\hline $2-3$ days & 23 & 10.5 \\
\hline Less than 2 days & 38 & 17.1 \\
\hline Never & 154 & 70 \\
\hline \multicolumn{3}{|l|}{ Place of consuming first meal } \\
\hline Before leaving home & 63 & 29.9 \\
\hline On way to school & 01 & 0.5 \\
\hline At school (Before bell) & 14 & 06.6 \\
\hline At school (During interval) & 133 & 63 \\
\hline No breakfast taken & 0 & - \\
\hline
\end{tabular}

Of $148(70 \%)$ children who left home without breakfast; $133(63 \%)$ ate the first meal during the mid-morning school break. A further $14(6.6 \%)$ ate "before the first bell", and one $(0.5 \%)$ ate "on the way to school". The number starting school without consuming a solid meal was 133 (63\%). Three children said breakfast was served by the school. Another had this provision only on one day, each week. The 133 children who ate during the school break gave the following reasons for leaving home without breakfast: "No appetite or not hungry after morning beverage" 98 (73.5\%), "Do not like to eat very early in the morning" $29(22 \%)$ and "No time" 6 (4.5\%). Seventy five (34\%) left home before 7 am and a further $51 \%$ left between 7 and $7.30 \mathrm{am}$.

Maternal awareness on importance of breakfast was high. All mothers said that "breakfast is essential" and $97 \%$ said it was "no less important than lunch". 
However only $141(64 \%)$ thought that a balanced meal including fruits and vegetables should be consumed for breakfast. All mothers rated rice or rice flour based meals as better than wheat flour based foods in terms of nutrition and health. None thought that fast foods were healthy (Table 3).
Even though rice based food items were the most commonly prepared breakfast, fast foods were the most liked food items by 147 (66.8\%). Wheat flour based items were also preferred to rice by 64 $(29 \%)$. Rice was the first preference by only 40 $(18 \%)$ of children.

Table 3

Knowledge, attitude and practices of mothers regarding breakfast $(n=220)$

\begin{tabular}{|c|c|c|}
\hline Breakfast is essential & & $100 \%$ \\
\hline Breakfast is as important as lunch & & $97.1 \%$ \\
\hline Breakfast should be a balanced diet inclusive of & & \\
\hline vegetables and fruits & & $64.4 \%$ \\
\hline Rating as most suited for breakfast & & \\
\hline Rice based food & & $100 \%$ \\
\hline Wheat flour based food & & \\
\hline Fast foods & & \\
\hline Availability of time to prepare breakfast & & \\
\hline Had time to prepare breakfast & 165 & $75.0 \%$ \\
\hline Unemployed & 39 & $17.7 \%$ \\
\hline Employed & & \\
\hline No time to prepare breakfast & 14 & $6.4 \%$ \\
\hline Unemployed & 2 & $0.9 \%$ \\
\hline Employed & & \\
\hline
\end{tabular}

\section{Discussion}

We found that the proportion of school children leaving home without breakfast was as high as $70 \%$. Sixty three percent began the school day without eating a solid meal. Breakfast is known to increase attention, memory, test scores, motivation as well as physical performance in school children. It is therefore important that the current situation is remedied without delay.

The age group represented in our study was mostly primary school children. The reasons for not eating breakfast were directly or indirectly related to the early time of day. One third of children left home before 7.00 a.m. some as early as 6.00 a.m. and almost all before 7.30 a.m. There were many different reasons expressed for lack of time and even when they lived not far from the school, they left early and spent considerable lengths of time on the road before reaching their destination, because the school vans arrived very early.
Children who skipped breakfast told us they ate a snack or meal during the mid-morning break; this was unsupervised and the mother's were unsure of the intake. Schools providing breakfast was a rare occurrence. We recommend that schools provide supervised time to eat food brought from home, before the start of the first lesson.

Thirty seven percent of children who took breakfast in the break and $41 \%$ of those who ate before school were underweight. There was no significant association between the proportion of underweight children and the time of eating breakfast. (chi square value $0.364, p>0.05$ ) Limitations of this study are the lack of assessing quantities consumed and nutrient composition of commonly eaten food. Our overall finding was that rice and curry cooked for lunch was often served or packed as breakfast, and rice, the staple food of our country is the most commonly eaten ingredient for breakfast. In comparison with a previous study carried out in Kuliyapitiya, (a town in the North Western Province of Sri Lanka), we found school children to consume rice and rice flour based meals less 
commonly; and comparatively more children ate bread or wheat flour based foods ${ }^{5}$.

Childhood dietary habits are a significant determinant of adult diet ${ }^{6}$. Our finding that majority of children prefer to eat wheat flour based foods rather than the traditional breakfast is of concern with possible long term repercussions. Missing breakfast may encourage eating of less wholesome foods, and make fast foods and snacks a habit.

Diets of children should be viewed seriously because it can determine the health of an entire nation ${ }^{7}$. Many schools will claim they do not have sufficient resources to provide breakfast, which is a solution for children starting lessons on an early stomach. Unfortunately political will on this issue has waxed and waned in momentum before and after elections. We recommend that educational authorities play an active role in solving the problem of bad breakfast practices among school children, since it can lead to long term educational and health implications.

\section{References}

1. Dupuy NA. Focus on Nutrition $1^{\text {st }}$ ed. New York: Mosby; 1995.
2. Ministry of Health, Nutrition and Welfare. Food Based Dietary Guidelines for Sri Lankans, 2002.

3. Kowtaluk H. Discovering Foods and Nutrition. $1^{\text {st }}$ ed. Illinois: Glencoe/McGrawHill Companies; 2001.

4. Wardlaw GM. Contemporary Nutrition: Issues and Insights. $5^{\text {th }}$ ed. New York: McGraw-Hill Companies; 2003.

5. Mikkilä V, Räsänen L, Raitakari OT, Pietinen P, Viikari J. Longitudinal changes in diet from childhood into adulthood with respect to risk of cardiovascular diseases. European Journal of Clinical Nutrition 2004; 58(7):1038-45.

6. Thilakarathne L. Study on Breakfast Practices of School Children in Kuliyapitiya Area. Retrieved July 17, 2006, from http://www.nutsoc.net/newsletter9.htm

7. Janasaviya: Ministry of Planning and Implementation. International Conference on Nutrition; Sri Lanka country report, 1992 